\title{
The importance of executive leadership in creating a post-merged organisational culture conducive to effective performance management
}

\begin{tabular}{|c|c|}
\hline \multicolumn{2}{|c|}{$\begin{array}{l}\text { Authors: } \\
\text { Gary W. Paul } \\
\text { David M. Berry }\end{array}$} \\
\hline \multicolumn{2}{|c|}{$\begin{array}{l}\text { Affiliations: } \\
{ }^{1} \text { Department of Human } \\
\text { Resources, Nelson Mandela } \\
\text { Metropolitan University, } \\
\text { South Africa }\end{array}$} \\
\hline \multicolumn{2}{|c|}{$\begin{array}{l}\text { Correspondence to: } \\
\text { Gary Paul }\end{array}$} \\
\hline \multicolumn{2}{|c|}{$\begin{array}{l}\text { Email: } \\
\text { gary.paul@nmmu.ac.za }\end{array}$} \\
\hline \multicolumn{2}{|c|}{$\begin{array}{l}\text { Postal address: } \\
\text { PO Box } 77000 \text {, Port Elizabeth } \\
6031 \text {, South Africa }\end{array}$} \\
\hline \multicolumn{2}{|c|}{$\begin{array}{l}\text { Dates: } \\
\text { Received: } 11 \text { Nov. } 2011 \\
\text { Accepted: } 26 \text { Aug. } 2012 \\
\text { Published: } 14 \text { Jan. } 2013\end{array}$} \\
\hline \multicolumn{2}{|c|}{$\begin{array}{l}\text { How to cite this article: } \\
\text { Paul, G.W., \& Berry, D.M. } \\
\text { (2013). The importance } \\
\text { of executive leadership } \\
\text { in creating a post- } \\
\text { merged organisational } \\
\text { culture conducive to } \\
\text { effective performance } \\
\text { management. SA Journal } \\
\text { of Human Resource } \\
\text { Management/SA Tydskrif vir } \\
\text { Menslikehulpbronbestuur, } \\
\text { 11(1), Art. \#446, } 15 \text { pages. } \\
\text { http://dx.doi.org/10.4102/ } \\
\text { sajhrm.v11i1.446 }\end{array}$} \\
\hline \multicolumn{2}{|c|}{$\begin{array}{l}\text { Copyright: } \\
\text { (C) 2013. The Authors. } \\
\text { Licensee: AOSIS } \\
\text { OpenJournals. This work } \\
\text { is licensed under the } \\
\text { Creative Commons } \\
\text { Attribution License. }\end{array}$} \\
\hline \multicolumn{2}{|l|}{ Read online: } \\
\hline 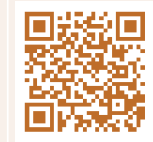 & $\begin{array}{l}\text { Scan this QR } \\
\text { code with your } \\
\text { smart phone or } \\
\text { mobile device } \\
\text { to read online. }\end{array}$ \\
\hline
\end{tabular}

Orientation: Focus was placed on the important role of executive management in creating a post-merged organisational culture conducive to effective performance management.

Research purpose: To develop a theoretical model from the insights gleaned from the literature study, interviews with senior human resource (HR) practitioners at participating institutions and the empirical study. Based on the empirical findings, this model was refined and resulted in the eight-step integrated post-merged organisational culture creation model.

Motivation for the study: The negligible attention given to the design of mechanisms supportive of post-merged organisational culture creation emphasised the need for this study. The high percentage of merger failures attributable to ineffective post-merged organisational culture integration further contributed.

Research design, approach and method: A quantitative study was conducted at three merged South African higher education institutions, namely Nelson Mandela Metropolitan University, Cape Peninsula University of Technology and Durban University of Technology. Respondents occupied the following functional categories: executive management, senior and line management, HR practitioners and non-HR or non-management.

Main findings: Respondents perceived the role of executive management to be the most important step of the theoretical model which formed the basis for the empirical survey questionnaire. This step, which obtained the highest summated mean score in all three institutions and across all functional categories, was depicted as Step 5 of the model.

Practical/managerial implications: The refined eight-step integrated post-merged organisational culture creation model will significantly enhance the creation of a post-merged organisational culture conducive to effective performance management.

Contribution/value-add: This study addressed the void regarding a model to guide the creation of a post-merged organisational culture conducive to effective performance management in higher education institutions as well as merged corporate organisations.

\section{Introduction}

\section{Problem statement}

The main problem statement of this study focuses on strategies to create a post-merged organisational culture which is conducive to effective management of performance. Froneman (2003) contends that higher education is one of the most rapidly changing sectors of society. He further argues that the successful leadership and management of these changes requires the permanent transformation of higher education from the 'what is' state into the 'what should be or must be' state (Froneman, 2003). This study aims to focus on the changes and challenges imposed on higher education institutions in South Africa as a result of the mergers specifically, as well as the concomitant implications for organisational culture and performance management in these post-merged institutions.

Martin and Roodt (2008) express the view that a merger can be considered as a significant life event for both an organisation and its employees. How employees cope with and respond to a merger has a direct impact on the organisation's performance in the short to medium term. Muller (2006, pp. 198-207) concurs with this view, pointing out that mergers can cause staff to feel 'overstretched' and 'overburdened'. The logical consequence of these experiences is a negative impact on the performance of the organisation.

Bresler (2007) argues that, normally, mergers form part of a general strategy for diversification or growth and are underpinned by a due-diligence process prior to the merger, during which 
merger candidates are evaluated in order to determine the strategic fit. She further points out that in the case of the merging of higher education institutions, no such rationale or justification was provided, nor were the strategic or organisational synergies made explicit to affected parties. Instead, she contends, individual institutions were left with unclear expectations about their positioning in the merger as well as organisational culture fit. Institutions were left to their own devices and were expected to navigate through the process of culture integration without knowledge of the process and its effects (Bresler, 2007).

Locke (2007) suggests that mergers in higher education, like commercial mergers, fail to deliver their promised or desired value as a result of organisational culture clashes. A lack of organisational culture integration often translates into strategic, financial and operational non-performance in a merged institution (Locke, 2007). Locke (2007) also points out that the longer term benefit of managing higher education mergers with the necessary cultural sensitivity is the unleashing of a wave of creativity amongst staff, creating greater openness to new ideas, a dynamic mix of interests and expertise, and unanticipated synergies, leading to enhanced teaching portfolios, increased research outputs and new collaborations with external stakeholders.

\section{The key focus of the study}

This study makes a significant contribution in an area that is crucial to higher education. There has been a paucity of studies of post-mergers and scant attention has been given to the design and implementation of mechanisms that could support the post-merged organisational culture creation process.

\section{Background to the study}

In January 2000, the Minister of Education, the late Professor Kader Asmal, requested the Council on Higher Education (CHE) to provide him with a concrete proposal in respect of the size and shape of higher education in South Africa. This proposal was required to give direction to institutional restructuring with the view of ensuring long-term affordability and sustainability of higher education (Council on Higher Education, 2000). In 2002, the South African government approved the restructuring of higher education which resulted in the mergers and incorporations within the sector (BuaNews, 2003). However, there was strong opposition to the mergers and it was contended that the process was driven by government through a mixture of politics, legislation and persuasion (Jansen, 2003).

Schultz (2009) echoes the sentiment that mergers have been a major and highly contested theme in higher education in the past decade. In reference to the South African context, she argues that a political decision was made to change the higher education landscape. This has had the unintended consequence of lower organisational commitment and potentially lower employee job performance in the mergerbound higher education institutions as a result of the slapdash manner in which the restructuring occurred. Furthermore, she argued that employees' responses to a merger have an impact on institutional performance and that serious consideration should be given to realigning the people management component to support the business strategy and to produce the desired level of organisational performance (Schultz, 2009).

Ramphele (2009) argues that the transformation of education and training in South Africa could have been better effected by learning from the experiences of countries such as Finland, Ireland, South Korea and even Zimbabwe, who were all able to increase mass access to education and training whilst improving the quality of outcomes. She further argues that improved access to education in South Africa has not necessarily translated into improved outcomes, such as in the lives of the poor (Ramphele, 2009). It can be concluded that the conditions mentioned above could only serve to add to the leadership challenges to be encountered during the merger process and therefore strengthening the case for effective executive leadership during such times.

The purpose of this article is, however, to place special focus on the survey findings related to Step 5 ('integration and alignment of executive management') of Phase 3 ('initiate the integration and alignment process') in the eight-step theoretical model which underpinned the creation of the survey questionnaire (explained in a later section). The typical organisational structure of a South African tertiary institution's executive, senior management and line management structure is depicted in Figure 1.

The empirical study required responses from executive management (vice-chancellor, deputy vice-chancellor, executive directors and executive deans), senior management (senior directors and directors), line managers and human resource (HR) practitioners. Executive management members are typically responsible for directing the development of strategies and determining policies within the institution. Senior management members are usually required to direct the implementation of strategies and policies. Line managers are required to ensure that the employees working in their departments execute their functions in accordance with the operational plans, based on the strategies, within the relevant policy parameters.

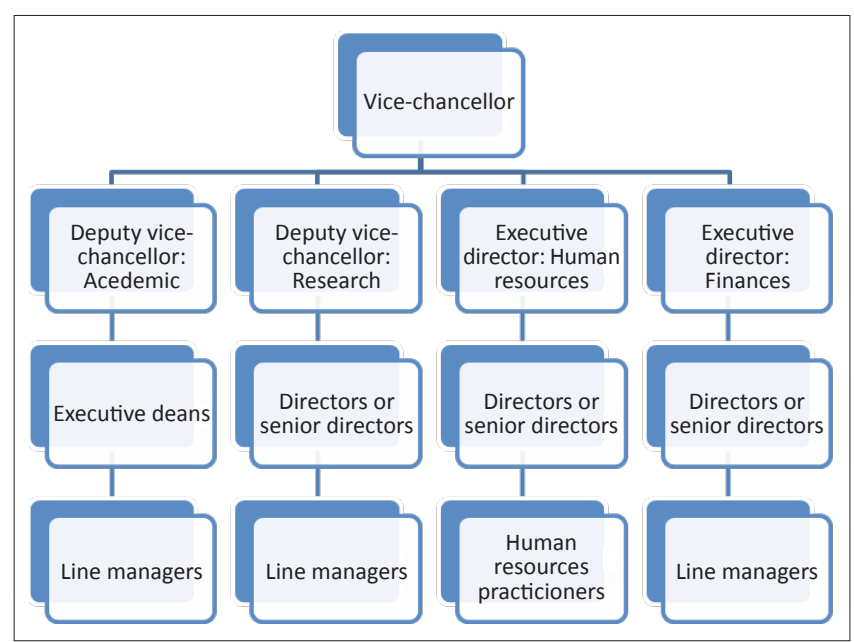

FIGURE 1: Typical South African tertiary institution organisational structure. 
Like most tertiary institutions in South Africa, those that participated in this study utilise the Peromnes grading system. This system takes into account the following eight factors in determining the level of a particular job:

- problem solving

- consequence of judgement

- pressure of work

- knowledge

- job impact

- comprehension

- educational qualifications

- further training and experience.

Few mergers reach their stated growth and value creation targets and more than half of all merger transactions destroy value, resulting in lower profitability. These outcomes can be attributed to a lack of effective pre-merger preparation (Roland Berger Strategy Consultants, 2010). They further point out that successful pre-merger planning requires a sound strategy, a deep understanding of operational, financial, legal, taxation and cultural issues related to the merging organisations (Roland Berger Strategy Consultants, 2010).

According to Goodboy (2010), pre-merger planning and preparation are two critical success factors in respect of mergers. He also highlights the need to focus on legal, financial, taxation and cultural aspects, as well as an operational due diligence study. He suggests that an understanding in relation to these matters can be achieved through meetings between the management of the merging organisations, as well as ad hoc interviews with employees, suppliers and other stakeholders (Goodboy, 2010).

Carleton and Lineberry (2004) place strong emphasis on a pre-merger culture due diligence study. This, they argue, can be done by means of qualitative and quantitative methodologies. Qualitative methodologies include interviews, focus groups, workplace observations and documentation reviews. Researchers could capture the voice of the culture and the employees by collecting their verbal comments and arranging the data according to predetermined culture attributes or according to the types of cultural behaviours that are displayed. Quantitative methodologies are shaped by the qualitative data obtained from the methods mentioned above. It is advisable to administer a Web-based culture due diligence survey to a sample of the total population of the organisations involved in the merger in order to develop a high-level culture profile of each organisation.

According to Hall, Symes and Luescher (2004), the premerger phase in respect of higher education institutions in South Africa included the following aspects:

- institutional and joint structures to facilitate the merger process

- statutory and merger governance structures

- compliance with labour legislation

- due diligence in respect of assets, liabilities, obligations, systems and controls

- the development of a merger plan.

\section{Objectives of the study}

The main objective of this study was to work towards the development of an eight-step integrated post-merged organisational culture creation model to support the establishment of an organisational culture which is conducive to effective performance management in a post-merged environment. This main objective has been achieved through the pursuance of the following research objectives:

- Developing an integrated eight-step theoretical model from the literature sources, inclusive of the role of executive leadership in creating a post-merged organisational culture conducive to effective performance management.

- Through this article, focused attention will be placed on the importance of executive management in the creation of a post-merged organisational culture conducive to effective performance management.

- The literature to be relied upon in the 'Literature review' section of this article, explores the various results, views and variables related to the role of executive management in creating a post-merged organisational culture conducive to effective performance management.

- Gathering responses from sample of executive management, line and senior management, HR practitioners and nonHR or non-management employees from three merged institutions in South Africa.

- Integrating the results from the empirical study with the integrated eight-step theoretical model to develop an eightstep integrated post-merged organisational culture creation model for establishing a post-merged organisational culture conducive to effective performance management.

\section{Literature review}

The general gist of this section is to focus on literature which deals with the role of effective leadership in the development of a post-merged organisational culture conducive to effective performance management.

The promises made on paper in relation to future merger success often fail to materialise. Instead of creating new value, a merger can lead to value destruction. This is supported by recent literature on mergers and acquisitions which suggests that merger failure rates vacillate between $50 \%$ and $70 \%$. Reasons cited for the dismal merger success rates can be attributed to ineffective executive leadership or, worse still, simply an executive leadership vacuum (Stahl, 2004).

Scanlan (2005) points out that merger success can invariably be linked to executive leadership who understand how to build a business. He argues that a leader has to choose to spend the time and money up front in critically assessing the proposed community, economic and clinical merits of the merger, or spend immeasurably more time and money after the fact trying to fix what should have been figured out before closing the deal. Scanlan (2005) cautions that the single biggest challenge for executive leadership during a merger is blending people of different corporate and even national cultures, by working to reduce the psychological distances between them. A further critical leadership requirement is that the chief executive and his or her executive team must 
espouse visionary or values-based leadership. This brand of leadership reinforces the values inherent in the organisation's vision (Scanlan, 2005).

The findings of a study conducted by Booz Allen Hamilton (2001) suggests that merger success is inextricably linked to executive leadership rigour, which includes awareness of and attention to people, organisational culture issues and dealing with competing priorities and demands. Effective executive leadership drives disproportionate value towards the creation of an effective post-merged organisational culture integration and alignment process (Booz Allen Hamilton, 2001). The greater the frequency and magnitude of change, the more important leadership and organisational culture become. 'Leadership holds it all together during a merger.' It is considered to be a 'make or break' function in the post-merger environment (Able, 2007, pp. 1-9).

In their study on the management of post-merger integration for the creation of a successfully performing organisation, Macfarlane and Butterill (1999) present six principles that are critical in ensuring the effective transitioning of employees during a merger. The list of six includes the development of a clear, concise and accessible vision of the positive benefits of the merger and the involvement of visible, strong, cohesive executive leadership throughout the post-merger integration process. This post-merger executive leadership, referred to as the senior management group (SMG), advocated by Macfarlane and Butterill (1999), is required to take responsibility for embedding the accountability to lead the planning and implementation of the post-merger integration. Some of the specific roles of the SMG include developing a comprehensive set of transition planning principles and assumptions, convening a number of task forces and integration teams to assist in the planning and approving their work plans and final reports, as well as developing macrolevel indicators to monitor and evaluate the implementation of the post-merger integration (Macfarlane \& Butterill, 1999).

Denison Consulting (2007) illustrates that a successful and high-performing post-merged organisation was created in Reynolds American by implementing strategies which included:

- A pre-merged culture survey, which was conducted in order to determine the progress in respect of the culture integration as well as to identify the areas in need of immediate attention. Over 3000 employees completed this survey, which provided positive reinforcement for the integration work that had been done.

- Executive leadership's relentless communication of the vision, strategy and core values through open and meaningful conversations with all employees about the roadmap to post-merged success.

- Executive leadership's task to get as much input and employee reaction as possible prior to launching any major initiatives.

- Each functional team's task to present their employee engagement plans to the high performance culture team, which included executive leadership from Reynolds American.
The merger between London Guildhall University and University of North London (to form the London Metropolitan University) attributes much of its success to the fact that the members of the executive leadership (vice-chancellor, chief executive, three deputy vice-chancellors, director of finance, director of human resources, director of merger projects) were appointed ahead of the actual merger and that they were appointed on the basis of merit and suitability (Floud \& Corner, 2002). Designing and implementing an effective communication strategy were some of the key activities on which the executive leadership focused to ensure that staff would feel that they have been consulted and that they are being listened to. The executive team of the newly merged London Metropolitan University also spent much time and effort on planning, implementing and motivating change. In particular, the executive leadership attended to the philosophical direction and purpose of the merger instead of simply ascribing the merger of the two universities to an economic necessity (Floud \& Corner, 2002). The salient aspects related to the above two cases seem to corroborate the findings of this study in relation to the importance of the role of executive management in achieving a successful merger.

Merger failure, on the other hand, is said to occur when whatever the organisations had in mind that caused them to merge in the first place does not work out that way, or when shareholders suffer because operating results deteriorate instead of improving (Tobak, 2007). The list of the 10 most notorious merger failures that have been evaluated by Tobak (2007) include, AOL and Time Warner, HP and Compaq, Alcatel and Lucent, Daimler Benz and Chrysler, Excite and @Home, JDS Uniphase and SDL, Mattel and The Learning Company, Borland and Ashton Tate, Novell and WordPerfect, and National Semiconductor and Fairchild Semiconductor.

When considering the set of conclusions in Tobak's (2007) evaluation of the above listed failed mergers, one can argue that most, if not all, of the reasons for these merger failures can be attributed to executive leadership problems within the merging organisations. He concludes by providing the following summary of the reasons underpinning these merger failures:

- flawed corporate strategy for either or both companies

- one company 'sugarcoats' the truth, the other buys a PowerPoint pitch

- sub-optimum integration strategy for the situation

- culture misfit, loss of key employees after retention agreements are concluded

- the acquiring company's management team is inexperienced regarding merger-related matters

- flawed assumptions in synergies calculation

- ineffective corporate governance

- two desperate companies merge to form one big desperate company

- chief executive officer (CEO) of one or both companies sells the board and shareholders a bill of goods

- an impulse buy or panic sell gets shoved down the board's throat. 
It can be argued that the issues raised in Tobak's (2007) list provide compelling evidence of the types of activities on which the executive leadership within the context of a postmerged environment should be focusing in order to avoid the merger from being a failure. The above views make a compelling case for the critical role of effective executive leadership required to ensure merger success.

\section{Research design}

A basis for sound decision-making is the knowledge generated through a research process, rather than intuition, tradition or a gut-feel. This applies to decision-making in both the public and private sectors (Brynard \& Hanekom, 2006). Brynard and Hanekom (2006) point out that research or a scientific enquiry is a procedure used to obtain answers to questions and solve problems, in a systematic manner, with the support of verifiable facts. Meyers (2009) argues that a researcher finds a topic or a research problem that relates to the body of knowledge in a particular field or discipline, as illustrated in Figure 2.

According to Figure 2, research questions are usually derived from a theoretical body of knowledge, but they could also emerge from the prevailing business practice or the researcher's own intuition. In order to find answers to the questions arising from the research problems, the researcher elects a research method with which to find the empirical evidence systematically (Meyers, 2009).

The views expressed above place an important obligation on the researcher to ensure that the empirical questionnaire is capable of obtaining the desired answers to the various research questions, so as to create new knowledge or generate solutions to the research problems.

\section{Research approach}

The empirical study was conducted by means of a survey questionnaire which provided for the collection of large amounts of data. According to Brynard and Hanekom (2006), questionnaires provide respondents with an opportunity to carefully consider their responses to the various questions in the questionnaire. An added advantage is that large numbers of respondents, spread over a vast geographical area, can be reached by means of a questionnaire.

\section{Research method}

\section{Research participants}

A generalised communiqué was issued to all employees through the intranet at the respective participating institutions, inviting employees who fall within the following functional categories to participate in the survey:

- executive management

- line managers

- human resource practitioners

- non-HR or non-management.

As per data received from P. Newman (personal communication, June, 2010), E. Olkers (personal communication, September,
2010) and I. Tserpelis (personal communication, August, 2010), the total permanent employees within each of these institutions across the four functional categories are presented in Table 1.

As indicated in the note below Table 1, employees who did not have access to a dedicated personal computer and those employees in jobs below Peromnes grade 13 were excluded from the survey and are not reflected in the population in Table 1. Welman, Kruger and Mitchell (2005) and De Vos, Strydom, Fouche and Delport (2005) argue that a sample can only be described as representative if it has the same properties or characteristics as the population relevant to the research in question.

The populations in each of the three merged institutions involved in this study can be described as homogeneous on the basis that they comprise four sub-groups consisting of executive management, line management, HR practitioners and non-HR or non-management employees. These four functional categories which served as the four strata are mutually exclusive by virtue of the distinctive nature of functional roles within these institutions. The members across these four functional categories are, however, heterogeneous in respect of gender, home language and age. This application of the stratified random sampling method is consistent with the assertions of De Vos et al. (2005). This type of sampling is known to ensure that the different segments of a population are given sufficient representation in the sample. The sample size is selected in proportion to the number of persons in the stratum; in other words, larger samples from larger strata and smaller samples from smaller strata (De Vos et al., 2005).

The HR director (or a designated substitute) and the information technology (IT) person responsible for IT-related research support within each of the participating institutions assisted in the institution-wide dissemination of the request

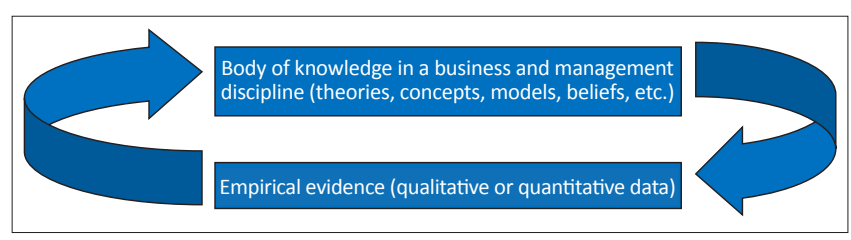

Source: Meyers, M.D. (2009). Qualitative research in business management. Thousand Oaks: Sage Publications

FIGURE 2: A model of research in business and management.

TABLE 1: Permanent employees in the three study institutions across the four functional categories广ं.

\begin{tabular}{llll}
\hline Functional category & NMMU & CPUT & DUT \\
\hline Executive management & 24 & 14 & 19 \\
Line management & 400 & 312 & 625 \\
$\begin{array}{l}\text { HR practitioners } \\
\begin{array}{l}\text { Non-HR and non-management } \\
\text { employees }\end{array}\end{array}$ & 22 & 23 & 32 \\
\hline Total & $\mathbf{1 3 9 6}$ & 891 & 350 \\
\hline
\end{tabular}

Source: P. Newman (personal communication, June, 2010); E. Olkers (personal communication, September, 2010); I. Tserpelis (personal communication, August, 2010)

September, 2010); I. Tserpelis (personal conmunicat, August, 2010) HR, human resources; NMMU, Nelson Mandela Metropolitan University;
Peninsula University of Technology; DUT, Durban University of Technology.

$\dagger$, Excluding permanent employees who did not have access to a dedicated personal computer or were in a job below Peromnes grade 13. 
to participate in the survey. With the assistance of the ITperson, a follow-up was conducted by issuing two reminders to all employees within each of the four functional categories.

\section{Measuring instrument}

The survey in this study was made available to potential respondents by means of an Internet-based questionnaire. Respondents were required to complete the questionnaire after accessing it through the hyperlink that was inserted into the body of the communiqué. The questions that were included in the questionnaire used in this study were formulated in accordance with the guidelines provided by Welman et al. (2005), and Struwig and Stead (2001). The majority of the questions were close-ended; however, at the end of Sections 2, 3, 4 and 5, provision was made for respondents to provide any information that they considered relevant to the subject covered in those particular sections. Each section had an appropriately phrased introduction related to the subject covered. Questions were formulated in a straightforward manner in order for respondents to easily grasp what was being asked. The questionnaire was laid out in an uncluttered manner to avoid possibly confusing respondents.

\section{Research procedure}

Given the stringent protocols which exist in relation to conducting research within higher education institutions, the researcher also submitted formal requests to conduct the empirical research study to the vice-chancellors of the participating institutions.

\section{Response rates}

Figure 3 provides a visual illustration of the tabulated response rate per merged institution. It is clear from the information contained herein that the Nelson Mandela Metropolitan University (NMMU) employees completed the majority of the questionnaires compared to that of the Cape Peninsula University of Technology (CPUT) and the Durban University of Technology (DUT) as separate institutions. However, given the low response rates from CPUT and DUT, the responses from these two institutions were combined for purposes of statistical analyses.

The NMMU responses were slightly higher from the former Port Elizabeth Technikon (43\%) than the former University of Port Elizabeth (40\%). The CPUT responses included more respondents from the former Cape Technikon (27\%) than from the former Peninsula Technikon (14\%). At DUT, more respondents originated from the former Natal Technikon (26\%) than from the former ML Sultan Technikon (16\%). Question 2 in Section 1 of the questionnaire made provision for respondents who did not work for any of the listed premerged institutions by allowing respondents to select the 'other' option. The researcher analysed and categorised the 'other' options into academic (8\%) and non-academic (9\%) institutions, as illustrated in Table 2 .

Table 3 indicates that responses across the four categories from NMMU and CPUT-DUT are marginally different. It is clear that the majority of the respondents are from the non-
HR or non-management ('other') category. At NMMU, 66\% of respondents were from the 'other' category, compared with $62 \%$ from CPUT-DUT. Executive responses from NMMU and CPUT-DUT were $5 \%$ and $4 \%$ of the total responses, respectively. Line managers from NMMU and CPUT-DUT represented $66 \%$ and $62 \%$ of the total responses, respectively. The number of respondents per functional category is a representative sample of the total number of permanent employees who occupy the various categories per institution, as illustrated in Figure 3.

\section{Statistical analysis}

The research findings have been organised and presented in tabular form. Tables 1-9 referred to in this paper were generated with the aid of the DPSS version 11.0 software

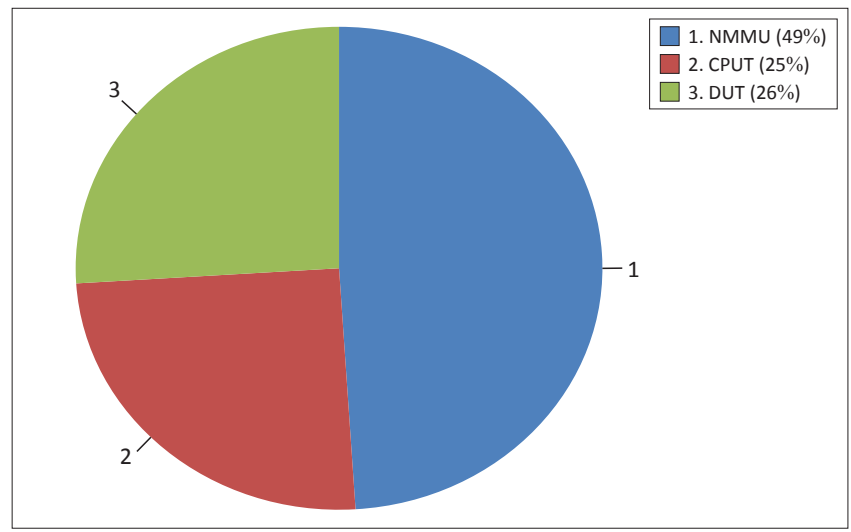

NMMU, Nelson Mandela Metropolitan University; CPUT, Cape Peninsula University of Technology; DUT, Durban University of Technology.

$N=276$.

FIGURE 3: Percentage of respondents per merged institution.

TABLE 2: Response rates per merged and pre-merged institution.

\begin{tabular}{|c|c|c|c|c|c|c|}
\hline \multirow{3}{*}{$\begin{array}{l}\text { Name of pre-merged } \\
\text { institutions }\end{array}$} & \multicolumn{6}{|c|}{ Name of merged institution } \\
\hline & \multicolumn{2}{|c|}{ NMMU } & \multicolumn{2}{|c|}{ CPUT-DUT } & \multicolumn{2}{|c|}{ Total } \\
\hline & $N$ & $\%$ & $N$ & $\%$ & $N$ & $\%$ \\
\hline UPE & 55 & 40 & 0 & 0 & 55 & 20 \\
\hline PE Technikon & 59 & 43 & 0 & 0 & 59 & 21 \\
\hline Peninsula Technikon & 0 & 0 & 20 & 14 & 20 & 7 \\
\hline Cape Technikon & 0 & 0 & 38 & 27 & 38 & 14 \\
\hline ML Sultan Technikon & 0 & 0 & 23 & 16 & 23 & 8 \\
\hline Natal Technikon & 0 & 0 & 37 & 26 & 37 & 14 \\
\hline Other academic & 9 & 7 & 10 & 8 & 19 & 7 \\
\hline Other Non-academic & 13 & 10 & 12 & 9 & 25 & 9 \\
\hline Total & 136 & 100 & 140 & 100 & 276 & 100 \\
\hline
\end{tabular}

UPE, University of Port Elizabeth; PE, Port Elizabeth; NMMU, Nelson Mandela Metropolitan University; $N$, number of respondents; CPUT, Cape Peninsula University of Technology; DUT, Durban University of Technology.

TABLE 3: Functional category per merged institution.

\begin{tabular}{|c|c|c|c|c|c|c|}
\hline \multirow[t]{3}{*}{ Functional category } & \multicolumn{6}{|c|}{ Name of merged institution } \\
\hline & \multicolumn{2}{|c|}{ NMMU } & \multicolumn{2}{|c|}{ CPUT-DUT } & \multicolumn{2}{|c|}{ Total } \\
\hline & $N$ & $\%$ & $N$ & $\%$ & $N$ & $\%$ \\
\hline Executive management & 7 & 5 & 6 & 4 & 13 & 5 \\
\hline Line management & 32 & 24 & 38 & 27 & 70 & 25 \\
\hline HR practitioner & 7 & 5 & 9 & 7 & 16 & 6 \\
\hline Other & 90 & 66 & 87 & 62 & 177 & 64 \\
\hline Total & 136 & 100 & 140 & 100 & 276 & 100 \\
\hline
\end{tabular}

$\mathrm{HR}$, human resources; NMMU, Nelson Mandela Metropolitan University; $N$, number of respondents; CPUT, Cape Peninsula University of Technology; DUT, Durban University of Technology. 
package, as per D. Venter (personal communication, October, 2010), by using a download of the data that were stored in a password-protected data-repository which developed as questionnaires were completed and submitted electronically via the Internet. Descriptive and inferential statistics were used to analyse the raw data obtained from the survey. The descriptive data included measures of central tendency and dispersion of selected variables. The scoring of Sections 2-5 of the questionnaire made use of a Likert-type scale. The questionnaire consisted of six sections. Section 1 dealt with respondents' biographical details. In Section 2 of the questionnaire, numerical values, namely 1 ('not important'), 2 ('fairly important') and 3 ('very important'), were used to enable the quantitative analysis of the results. In addition to using this scale to indicate importance, respondents also had to indicate whether the assessment should be formal or informal or that there should not be an assessment at all. Numerical values, namely 1 ('no assessment'), 2 ('informal assessment') and 3 ('formal assessment') were also assigned here to enable the quantitative analysis of the results. In Sections 3-5, respondents were requested to indicate whether an aspect was 'not important', 'slightly important' or 'very important'. The same numerical values as in Section 2 of the questionnaire were used for 'not important', 'fairly important' and 'very important' in order to enable the quantitative analysis of results.

\section{Results}

The results in this study have been derived by means of descriptive and inferential statistics. Descriptive statistics were applied to determine the summated mean scores which related to the various phases and process steps of the model in Figure 4, as well as the summated scores for the two groups of institutions (NMMU and CPUT-DUT) and their functional categories. Inferential statistics employed in this study are illustrated in Table 4.

Explanations related to the application and interpretations of the different values derived from each of these tests are provided, where a specific test was used, in the various tables and graphs that are presented in this article. The results in Table 5 provide information related to the significance of correlations between the various phases and their associated process steps of the integrated theoretical model in Figure 2.
TABLE 4: Inferential statistical tests used in this study.

\begin{tabular}{llccc}
\hline Test name & Test type & Small & Moderate & Large \\
\hline$t$-test & Cohen's $d$ & $0.20<d<0.05$ & $\mathbf{0 . 0 5}<\boldsymbol{d}<\mathbf{0 . 8 0}$ & $\boldsymbol{d}>\mathbf{0 . 8 0}$ \\
ANOVA & Eta $\eta^{2}$ & $0<\eta^{2}<0.09$ & $\mathbf{0 . 0 9}<\eta^{2}<0.25$ & $\eta^{2}>\mathbf{0 . 2 5}$ \\
Chi-square & Cramér's $V$ & - & - & - \\
& $d f^{*}=\mathbf{1}$ & $0.10<V<0.30$ & $\mathbf{0 . 3 0}<\boldsymbol{V}<\mathbf{0 . 5 0}$ & $\boldsymbol{V}>\mathbf{0 . 5 0}$ \\
& $d f^{*}=2$ & $0.07<V<0.21$ & $0.21<V<0.35$ & $V>0.35$ \\
& $d f^{*} \geq 3$ & $0.06<V<0.17$ & $0.17<V<0.29$ & $V>0.29$ \\
Correlation & Correlation $r$ & $0.00<r^{2}<0.09$ & $\mathbf{0 . 0 9}<r^{2}<0.25$ & $r^{2}>\mathbf{0 . 2 5}$ \\
\hline
\end{tabular}

Source: D. Venter (personal communication, October, 2010)

$t$-test, if the $d$-value is below 0.05 , it implies that there is a statistically significant difference between the two data sets; ANOVA, Analysis of variance; Chi-square test, difference between group-means is considered as statistically significant if a $p$-value of less than 0.05 is obtained Cohen's $d$, Cohen's $d$ is an effect size used to indicate the standardised difference between two means; Eta $\eta^{2}$, effect size is a value which allows reflects the extent of the impact that the independent variable had on the dependent variable in an experimental study; Cramér's $V$, Cramer's $V$ is a statistical method of calculating correlations in tables which have more than two rows and two columns; $d f^{*}$, degrees of freedom refer to the number of values in a study that are free to vary; $r^{2}$, refers to the square of the sample correlation coefficient between the outcomes and their predicted values. In the case of simple linear regression, it refers to the difference between the outcome and the values being used for prediction. Figures in bold imply that there is a statistically significant difference between the two data sets.

The data above the diagonal line in Table 5 relates to the responses obtained from NMMU and the data below the line to responses obtained from CPUT-DUT.

The scores indicated in bold in Table 5 denote a significant correlation between those particular phases' summated scores (depicted by the letter ' $\mathrm{P}$ ') in terms of importance within the two groups (NMMU and CPUT-DUT). A correlation is statistically significant if $(|r|>0.168$ for NMMU and $|r|>0.166$ for CPUT-DUT) and practically significant of $(|r|>0.30)$ significant for both NMMU and CPUT-DUT. The correlations indicate congruence between the different institutions in terms of the importance of these factors, as well as the interrelatedness of these factors. These correlations also confirm the reliability of the items in the questionnaire and their relation to the specific phases. It is also evident from the scores in Table 5 that P3.1 (depicted as Step 5 in Figure 4) correlates positively with P3.2 (depicted as Step 6 in Figure 4) and P3.3 (depicted as Step 7 in Figure 4). The scores in Table 5 also indicate a positive correlation between P3.1 and P3 (depicted as the entire Phase 3 in Figure 4) and P4 (depicted as Phase 4, the Step 8 in Figure 4), as well as the moderating variables (MV) at both NMMU (above the diagonal line) and CPUT-DUT (below the diagonal line). All the interactions between phases, process steps and the MV listed in Table 5 are indicative of significantly different correlations between NMMU and CPUT-DUT.

TABLE 5: Correlations of statistical significance between summated scores obtained from NMMU and CPUT-DUT for phases and process steps of integrated theoretical model which formed the basis for the survey questionnaire.

\begin{tabular}{|c|c|c|c|c|c|c|c|c|c|c|}
\hline & P1.1 & P1.2 & P1.3 & P1 & P3.1 & P3.2 & P3.3 & P3 & P4 & MV \\
\hline P1.1 & - & 0.643 & 0.496 & 0.809 & 0.125 & 0.000 & 0.009 & 0.048 & 0.138 & 0.387 \\
\hline P1.2 & 0.706 & - & 0.473 & 0.861 & 0.058 & 0.037 & -0.040 & 0.019 & 0.156 & 0.358 \\
\hline P1.3 & 0.554 & 0.577 & - & 0.815 & 0.089 & -0.018 & 0.158 & 0.099 & 0.216 & 0.407 \\
\hline P1 & 0.858 & 0.895 & 0.829 & - & 0.103 & 0.009 & 0.056 & 0.068 & 0.210 & 0.461 \\
\hline P3.1 & 0.254 & 0.276 & 0.211 & 0.287 & - & 0.342 & 0.396 & 0.708 & 0.443 & 0.341 \\
\hline P3.2 & 0.163 & 0.309 & 0.164 & 0.252 & 0.758 & - & 0.329 & 0.766 & 0.354 & 0.219 \\
\hline P3.3 & 0.186 & 0.195 & 0.202 & 0.226 & 0.768 & 0.589 & - & 0.783 & 0.424 & 0.259 \\
\hline P3 & 0.219 & 0.290 & 0.213 & 0.283 & 0.926 & 0.882 & 0.879 & - & 0.532 & 0.351 \\
\hline P4 & 0.206 & 0.324 & 0.210 & 0.292 & 0.607 & 0.588 & 0.589 & 0.664 & - & 0.508 \\
\hline MV & 0.302 & 0.302 & 0.392 & 0.386 & 0.599 & 0.545 & 0.611 & 0.653 & 0.601 & - \\
\hline
\end{tabular}

The scores indicated in bold denote a significant correlation between those particular phases' summated scores, in terms of importance within the two groups (NMMU and CPUT-DUT). The data above the diagonal line in the table relate to the responses obtained from NMMU and the data below the line to responses obtained from CPUT-DUT. A correlation is statistically significant if $|r|>0.168$ for NMMU and $|r|>0.166$ for CPUT-DUT and practically significant if $|r|>0.30$ for NMMU and CPUT-DUT.

P1.1, Step 1; P1.2, Step 2; P1.3, Step 3; P1, the entire Phase 1; P3.1, Step 5; P3.2, Step 6; P3.3, Step 7; P3, the entire Phase 3; P4, Phase 4 Step 8; MV, moderating variables; NMMU, Nelson Mandela Metropolitan University; CPUT, Cape Peninsula University of Technology; DUT, Durban University of Technology. 
The $p$-values are all below 0.05 , suggesting that the correlations listed in Table 6 are statistically significantly different between NMMU and CPUT-DUT in terms of the chi-square test for statistical significance. The $V$-values range between 0.14 and 0.37 (refer to Table 6), suggesting that the difference in the correlations between NMMU and CPUT-DUT, as listed in Table 6, range between small and moderately significant in terms of the Cramér's $V$-test for practical significance. It is also noteworthy that P3.1 (the role of executive leadership in creating an organisational culture conducive to effective performance management in a post-merged environment) did not show any significant or practical difference from all other variables at NMMU and CPUT-DUT.

In terms of the above analysis, it is significant to note that respondents at NMMU and CPUT-DUT did not necessarily express similar perceptions regarding the importance of the other aspects between which the correlations in Table 5 were made. This difference in perceptions could possibly be attributed to the differences in the nature of the institutions, as NMMU is a comprehensive university and CPUT and DUT universities of technology.

\section{Ethical considerations}

It was a requirement for the study to obtain written approval from the research ethics committees of the participating institutions. The researcher duly complied with that institutional requirement and written approval was obtained from each of the participating institutions.

\section{Potential benefits and hazards}

Participation in the survey posed no risks or dangers to respondents and no information will be disclosed that may compromise the nature of responses received. The responses received were stored in a data repository which did not allow access to any party other than the researcher. Respondents from the three participating institutions could benefit from the findings of this study should their respective institutions elect to implement the recommendations.

\section{Recruitment procedures}

Respondents were under no obligation to respond. With the assistance of the various IT-departments, the researcher issued an electronic invitation by means a generalised communiqué at the three participating institutions. The communiqué included a hyperlink to the Web-based questionnaire which allowed respondents access to the survey questionnaire.

\section{Informed consent}

Respondents who participated in the empirical study were fully informed of the purpose of the study and could seek clarity from the researcher in the event of any queries or concerns.

\section{Data protection}

The responses received were stored in a password-protected data repository which was only accessible to the researcher. Under no circumstances was any part of the data accessed or accessible to any other persons.

\section{Trustworthiness}

In order to comply with the imperative of trustworthiness, the data in this study were subject to reliability and validity testing.

\section{Reliability}

Saunders, Lewis and Thornhill (2003, p. 101) caution that four threats need to borne in mind in relation to reliability. The first of these is subject or participant error. This refers to the variability in the results obtained, depending on when the questionnaire was completed. The second threat relates to participant bias, which occurs when respondents have provided answers that they believe their bosses would want them to provide. The third threat relates to observer error, which occurs when there are perhaps three researchers conducting interviews and who thus have the potential for at least three different approaches to eliciting responses. The fourth threat relates to observer bias, which occurs when three

TABLE 6: The chi-square test for statistical significance and the Cramér's $V$-test for practical significance.

\begin{tabular}{|c|c|c|c|c|c|c|}
\hline \multirow[t]{2}{*}{ Variables } & \multicolumn{2}{|c|}{ Correlations } & \multicolumn{4}{|c|}{ Significance of differences between NMMU and CPU-DUT } \\
\hline & NMMU & CPU-DUT & Chi-square; $d f=1$ & $p$-value & Cramer's $V$ & Level of significance \\
\hline P1.2:P3.2 & 0.037 & 0.309 & 5.36 & 0.021 & 0.14 & Small \\
\hline P3.1:P3.2 & 0.342 & 0.758 & 27.25 & 0.000 & 0.31 & Moderate \\
\hline P3.1:P3.3 & 0.396 & 0.768 & 24.01 & 0.000 & 0.29 & Small \\
\hline P3.1:P3 & 0.708 & 0.926 & 37.71 & 0.000 & 0.37 & Moderate \\
\hline P3.1:MV & 0.341 & 0.599 & 7.66 & 0.006 & 0.17 & Small \\
\hline P3.2:P3.3 & 0.329 & 0.589 & 7.55 & 0.006 & 0.17 & Small \\
\hline P3.2:P3 & 0.766 & 0.882 & 9.46 & 0.002 & 0.19 & Small \\
\hline P3.2:P4 & 0.354 & 0.588 & 6.28 & 0.012 & 0.15 & Small \\
\hline P3.2:MV & 0.219 & 0.545 & 10.23 & 0.001 & 0.19 & Small \\
\hline P3.3:P3 & 0.783 & 0.879 & 6.77 & 0.009 & 0.16 & Small \\
\hline P3.3:MV & 0.259 & 0.611 & 13.32 & 0.000 & 0.22 & Small \\
\hline P3:MV & 0.351 & 0.653 & 11.57 & 0.001 & 0.20 & Small \\
\hline
\end{tabular}

In the chi-square test, a difference between group means is considered as statistically significant if a $p$-value of less than 0.05 is obtained.

In terms of the Cramér's $V$-test for practical significance, a difference can be described as small, moderate or large. It is generally accepted that a difference is small if $10<V<0.30$, moderate if In terms of the Cramer's $V$-test
$V>0.30$ and large if $V>0.50$.

$V>0.30$ and large if $V>0.50$.
P1.1, Step 1; P1.2, Step 2; P1.3, Step 3; P1, the entire Phase 1; P3.1, Step 5; P3.2, Step 6; P3.3, Step 7; P3, the entire Phase 3; P4, Phase 4 Step 8; MV, moderating variables; NMMU, Nelson Mandela Metropolitan University; CPUT, Cape Peninsula University of Technology; DUT, Durban University of Technology; $d f$, degrees of freedom; $p$-value; probability value; Cramer's $V$, Cramer's $\vee$ is a statistical method of calculating correlations in tables which have more than two rows and two columns. 
interviewers have three different approaches to interpreting the replies. In relation to this study, the researcher was the only interviewer who conducted the face-to-face interviews with the senior HR practitioners, thus eliminating the threats related to observer error and observer bias. Additionally, the survey questionnaires were made available electronically, which allowed respondents to complete it at their own leisure. The threat of participant bias was further avoided on the basis that the responses to the questionnaires were completely confidential.

\section{Validity}

Validity is defined as the truth or trustworthiness of research findings (Struwig \& Stead, 2001, p. 18). Validity can be enhanced by means of triangulation, which implies that there must be various data sources, several investigators or various research methods. Different observers or respondents could provide different perspectives on the issue being investigated. Welman et al. (2005, p. 142) describe validity as the extent to which the research findings accurately represent what is really happening in the situation. This particular study applies the triangulation concept in that four different functional categories of employees (executives, line managers, HR practitioners and non-HR and non-management employees), of three different merged institutions (NMMU, CPUT and DUT), were required to express their perceptions of the same issues in the questionnaire.

\section{Discussion}

The outcome of this study has been the development of an eightstep integrated post-merged organisational culture creation model to support the establishment of an organisational culture which is conducive to effective performance management in a post-merged environment. A significant finding of this study has been the level of importance that respondents have attached to the role of the executive leadership in the creation of a post-merged organisational culture conducive to effective performance management. This article therefore specifically focuses on that particular finding.

Table 7 provides details of the eight questions under Section 3 of the questionnaire, which focused on aspects related to the role of the executive leadership in a post-merged environment. Step 5 in Phase 3 of the eight-step integrated post-merged organisational culture creation model addresses the integration and alignment of executive management.

\section{The Cronbach alpha test for internal consistency and reliability}

The Cronbach alpha is a statistical test that is utilised to establish the internal consistency and reliability of the items or statements included in the questionnaire. According to Struwig and Stead (2001), it is particularly useful in instances where a Likert-type scale has been applied. In essence, the Cronbach alpha quantifies how well the items or statements measure a specific concept or factor, such as executive management integration and alignment or line management integration and alignment, and whether the statements in the questionnaire or sub-scale belong together (Simon, 2008).

Table 8 depicts the Cronbach's coefficient alpha summated scores obtained for the various phases (P1, P2, P3, P4), process steps (P1.1, P1.2, P1.3, P3.1, P3.2, P3.3) and MV that were used in the survey questionnaire.

A Cronbach's alpha coefficient of greater than 0.70 , the recommended value for reliability, was observed for all of the factors, with values ranging from 0.78 to 0.90 . According to Simon (2008), a value of 0.06 is acceptable as sufficient evidence of adequate reliability for purposes of an exploratory study. The observed Cronbach's alpha coefficients relating to the factors in Table 6 all exceeded the 0.07 threshold, thus confirming the reliability of the summated scores derived from the individual measuring instruments.

Table 9 indicates the comparison between the summated mean scores of the participating institutions, as well as the functional categories in this study. This comparison is based on the means and standard deviations for summated responses related to each phase and its process steps (for Phases 1 [P1] and 3 [P3] only) of the model in Figure 2. The survey findings are presented as a combination of NMMU executive managers (EM), line managers (LM) and HR

\begin{tabular}{ll} 
TABLE 7: & Statements which required a response from executive management. \\
\hline Step 3 & Integration and alignment of executive management \\
\hline Q3-1 & $\begin{array}{l}\text { Executive managers should set an example by living the values of the } \\
\text { merged organisation. }\end{array}$ \\
Q3-2 & $\begin{array}{l}\text { Executive managers should walk-the-talk through faultless behavioural } \\
\text { modelling. }\end{array}$ \\
Q3-3 & $\begin{array}{l}\text { Executive managers should provide leadership in developing, } \\
\text { communicating and implementing the mission, vision and strategy of the } \\
\text { merged institution. }\end{array}$ \\
Q3-4 & $\begin{array}{l}\text { Executive managers need to deal with possible individual and collective } \\
\text { issues and differences amongst themselves through a formal issues- } \\
\text { resolution process. }\end{array}$ \\
Q3-5 & $\begin{array}{l}\text { Executive managers should provide direction, motivation, guidance and } \\
\text { clarity to employees in the merged organisation. }\end{array}$ \\
Q3-6 & $\begin{array}{l}\text { The leadership orientation of respective institutions needs to be } \\
\text { assessed. }\end{array}$ \\
Q3-7 & $\begin{array}{l}\text { Executive managers need to have meaningful conversations with all staff } \\
\text { about the roadmap to creating a high performance merged institution. }\end{array}$ \\
Q3-18 & $\begin{array}{l}\text { Executive and line managers should assist employees to adapt to the } \\
\text { organisational culture of the merged institution. }\end{array}$ \\
\hline Q, question.
\end{tabular}

$\mathrm{Q}$, question.

TABLE 8: The Cronbach alpha test summated scores in respect of the various phases and process steps as reflected in Figure 4.

\begin{tabular}{lll}
\hline Factors & Phases and process steps & $\begin{array}{l}\text { Summated } \\
\text { scores }\end{array}$ \\
\hline P1.1 & Conduct culture assessment & 0.78 \\
P1.2 & Assess human capital capability & 0.85 \\
P1.3 & Assess change readiness & 0.80 \\
P1 & Conduct pre-merger assessment & 0.79 \\
P3.1 & Executive management & 0.81 \\
P3.2 & Senior and line management & 0.82 \\
P3.3 & Total organisation & 0.84 \\
P3 & Initiate integration and alignment implementation process & 0.78 \\
P4 & Post-integration monitoring and evaluation measures & 0.90 \\
MV & Moderating variables & 0.81 \\
\hline P1.1, Step 1; P1.2, Step 2; P1.3, Step 3; P1, the entire Phase 1; P3.1, Step 5; P3.2, Step 6; P3.3,
\end{tabular}

Step 7; P3, the entire Phase 3; P4, Phase 4 Step 8; MV, moderating variables. 
TABLE 9: Comparison of summated scores in terms of institution and functional category.

\begin{tabular}{|c|c|c|c|c|c|c|c|c|c|c|}
\hline \multirow{3}{*}{$\begin{array}{l}\text { Process steps } \\
\text { and phases }\end{array}$} & \multirow{3}{*}{$\begin{array}{l}\text { Statistical } \\
\text { descriptors }\end{array}$} & \multicolumn{2}{|c|}{ Institution } & \multicolumn{2}{|c|}{ Functional category } & \multicolumn{4}{|c|}{ Institution: Functional category } & \multirow[t]{3}{*}{ Total } \\
\hline & & \multirow[t]{2}{*}{ NMMU } & \multirow[t]{2}{*}{ CPUT-DUT } & \multirow[t]{2}{*}{ EM-LM-HR } & \multirow[t]{2}{*}{ Other } & \multicolumn{2}{|c|}{ NMMU } & \multicolumn{2}{|c|}{ CPUT-DUT } & \\
\hline & & & & & & EM-LM-HR & Other & EM-LM-HR & Other & \\
\hline & $n$ & 136.00 & 140.00 & 99.00 & 177.00 & 46.00 & 90.00 & 53.00 & 87.00 & 276.00 \\
\hline \multirow[t]{5}{*}{ P1.1 } & Mean & 2.72 & 2.71 & 2.74 & 2.70 & 2.76 & 2.70 & 2.73 & 2.70 & 2.71 \\
\hline & SD & 0.29 & 0.37 & 0.29 & 0.36 & 0.22 & 0.33 & 0.35 & 0.39 & 0.34 \\
\hline & SEM & 0.03 & 0.03 & 0.03 & 0.03 & 0.03 & 0.03 & 0.05 & 0.04 & 0.02 \\
\hline & $95 \% \mathrm{Cl}-\mathrm{lo}$ & 2.67 & 2.65 & 2.69 & 2.64 & 2.70 & 2.63 & 2.63 & 2.61 & 2.67 \\
\hline & $95 \% \mathrm{Cl}-\mathrm{hi}$ & 2.77 & 2.77 & 2.80 & 2.75 & 2.83 & 2.77 & 2.82 & 2.78 & 2.75 \\
\hline \multirow[t]{5}{*}{ P1.2 } & Mean & 2.66 & 2.63 & 2.69 & 2.62 & 2.74 & 2.62 & 2.66 & 2.61 & 2.64 \\
\hline & SD & 0.47 & 0.48 & 0.39 & 0.52 & 0.35 & 0.52 & 0.41 & 0.52 & 0.48 \\
\hline & SEM & 0.04 & 0.04 & 0.04 & 0.04 & 0.05 & 0.05 & 0.06 & 0.06 & 0.03 \\
\hline & $95 \% \mathrm{Cl}-\mathrm{lo}$ & 2.58 & 2.55 & 2.62 & 2.54 & 2.63 & 2.51 & 2.54 & 2.50 & 2.59 \\
\hline & $95 \% \mathrm{Cl}-\mathrm{hi}$ & 2.74 & 2.71 & 2.77 & 2.69 & 2.84 & 2.73 & 2.77 & 2.73 & 2.70 \\
\hline \multirow{4}{*}{ P1.3 } & SD & 0.47 & 0.44 & 0.43 & 0.47 & 0.40 & 0.50 & 0.45 & 0.43 & 0.45 \\
\hline & SEM & 0.04 & 0.04 & 0.04 & 0.04 & 0.06 & 0.05 & 0.06 & 0.05 & 0.03 \\
\hline & $95 \% \mathrm{Cl}-\mathrm{lo}$ & 2.53 & 2.54 & 2.49 & 2.56 & 2.50 & 2.50 & 2.42 & 2.56 & 2.55 \\
\hline & $95 \% \mathrm{Cl}-\mathrm{hi}$ & 2.69 & 2.68 & 2.66 & 2.69 & 2.73 & 2.71 & 2.67 & 2.74 & 2.66 \\
\hline \multirow[t]{5}{*}{ P1 } & Mean & 2.66 & 2.65 & 2.67 & 2.65 & 2.71 & 2.64 & 2.64 & 2.65 & 2.66 \\
\hline & SD & 0.34 & 0.37 & 0.30 & 0.39 & 0.26 & 0.38 & 0.33 & 0.40 & 0.36 \\
\hline & SEM & 0.03 & 0.03 & 0.03 & 0.03 & 0.04 & 0.04 & 0.05 & 0.04 & 0.02 \\
\hline & $95 \% \mathrm{Cl}-\mathrm{lo}$ & 2.60 & 2.59 & 2.61 & 2.59 & 2.63 & 2.56 & 2.55 & 2.57 & 2.61 \\
\hline & $95 \% \mathrm{Cl}-\mathrm{hi}$ & 2.72 & 2.71 & 2.73 & 2.70 & 2.78 & 2.72 & 2.74 & 2.74 & 2.70 \\
\hline \multirow[t]{3}{*}{ P3.1 } & Mean & 2.83 & 2.85 & 2.85 & 2.83 & 2.85 & 2.83 & 2.85 & 2.84 & 2.84 \\
\hline & SD & 0.24 & 0.29 & 0.18 & 0.30 & 0.18 & 0.27 & 0.19 & 0.33 & 0.26 \\
\hline & SEM & 0.02 & 0.02 & 0.02 & 0.02 & 0.03 & 0.03 & 0.03 & 0.04 & 0.02 \\
\hline P3.2 & Mean & 2.76 & 2.78 & 2.75 & 2.78 & 2.75 & 2.77 & 2.76 & 2.79 & 2.77 \\
\hline & SD & 0.34 & 0.40 & 0.33 & 0.39 & 0.35 & 0.33 & 0.32 & 0.44 & 0.37 \\
\hline & SEM & 0.03 & 0.03 & 0.03 & 0.03 & 0.05 & 0.03 & 0.04 & 0.05 & 0.02 \\
\hline & $95 \% \mathrm{Cl}-\mathrm{lo}$ & 2.70 & 2.71 & 2.69 & 2.72 & 2.64 & 2.70 & 2.67 & 2.70 & 2.73 \\
\hline & $95 \% \mathrm{Cl}-\mathrm{hi}$ & 2.82 & 2.84 & 2.82 & 2.84 & 2.85 & 2.84 & 2.85 & 2.88 & 2.81 \\
\hline P3.3 & Mean & 2.79 & 2.79 & 2.78 & 2.80 & 2.75 & 2.82 & 2.80 & 2.77 & 2.79 \\
\hline & SD & 0.33 & 0.38 & 0.35 & 0.36 & 0.39 & 0.30 & 0.31 & 0.42 & 0.36 \\
\hline & SEM & 0.03 & 0.03 & 0.04 & 0.03 & 0.06 & 0.03 & 0.04 & 0.05 & 0.02 \\
\hline & $95 \% \mathrm{Cl}-\mathrm{lo}$ & 2.74 & 2.72 & 2.71 & 2.74 & 2.63 & 2.75 & 2.72 & 2.68 & 2.75 \\
\hline & $95 \% \mathrm{Cl}-\mathrm{hi}$ & 2.85 & 2.85 & 2.85 & 2.85 & 2.86 & 2.88 & 2.89 & 2.86 & 2.83 \\
\hline P3 & Mean & 2.79 & 2.80 & 2.79 & 2.80 & 2.78 & 2.80 & 2.81 & 2.80 & 2.80 \\
\hline & SD & 0.23 & 0.32 & 0.22 & 0.30 & 0.23 & 0.23 & 0.21 & 0.37 & 0.28 \\
\hline & SEM & 0.02 & 0.03 & 0.02 & 0.02 & 0.03 & 0.02 & 0.03 & 0.04 & 0.02 \\
\hline & $95 \% \mathrm{Cl}-\mathrm{lo}$ & 2.76 & 2.75 & 2.75 & 2.76 & 2.71 & 2.75 & 2.75 & 2.72 & 2.77 \\
\hline & $95 \% \mathrm{Cl}-\mathrm{hi}$ & 2.83 & 2.86 & 2.84 & 2.85 & 2.85 & 2.85 & 2.86 & 2.88 & 2.83 \\
\hline P4 & Mean & 2.64 & 2.66 & 2.60 & 2.67 & 2.62 & 2.65 & 2.59 & 2.70 & 2.65 \\
\hline & SD & 0.36 & 0.44 & 0.39 & 0.41 & 0.29 & 0.39 & 0.46 & 0.43 & 0.40 \\
\hline & SEM & 0.03 & 0.04 & 0.04 & 0.03 & 0.04 & 0.04 & 0.06 & 0.05 & 0.02 \\
\hline & $95 \% \mathrm{Cl}-\mathrm{lo}$ & 2.58 & 2.58 & 2.53 & 2.61 & 2.53 & 2.57 & 2.46 & 2.60 & 2.60 \\
\hline & $95 \% \mathrm{Cl}-\mathrm{hi}$ & 2.70 & 2.73 & 2.68 & 2.73 & 2.71 & 2.73 & 2.72 & 2.79 & 2.70 \\
\hline MV & Mean & 2.60 & 2.60 & 2.60 & 2.60 & 2.62 & 2.60 & 2.59 & 2.61 & 2.60 \\
\hline & SD & 0.30 & 0.33 & 0.25 & 0.35 & 0.23 & 0.33 & 0.27 & 0.36 & 0.31 \\
\hline & SEM & 0.03 & 0.03 & 0.03 & 0.03 & 0.03 & 0.03 & 0.04 & 0.04 & 0.02 \\
\hline & $95 \% \mathrm{Cl}-\mathrm{lo}$ & 2.55 & 2.55 & 2.55 & 2.55 & 2.55 & 2.53 & 2.51 & 2.53 & 2.56 \\
\hline & $95 \% \mathrm{Cl}-\mathrm{hi}$ & 2.65 & 2.66 & 2.65 & 2.65 & 2.69 & 2.66 & 2.66 & 2.68 & 2.64 \\
\hline
\end{tabular}

P1.1, Step 1; P1.2, Step 2; P1.3, Step 3; P1, the entire Phase 1; P3.1, Step 5; P3.2, Step 6; P3.3, Step 7; P3, the entire Phase 3; P4, Phase 4 Step 8; MV, moderating variables; $n$, number of respondents; SD, standard deviation; SEM, standard error of means; $95 \% \mathrm{Cl}$-lo, a low confidence interval; $95 \% \mathrm{Cl}$-hi, a high confidence interval. The confidence interval represents a range of values around the sample mean that include the true mean; NMMU, Nelson Mandela Metropolitan University; CPUT, Cape Peninsula University of Technology; DUT, Durban University of Technology; EM-LM-HR, sample mean that include the true mean; NMMU, Nelson Mandela Metropolitan University 
practitioners' (EM-LM-HR) responses compared to that of the non-HR or non-management employees ('other') of NMMU and CPUT-DUT, respectively. The NMMU and the CPUT-DUT combination are referred to as 'groups' for the purposes of providing clear explanations. These correlations also confirm the reliability of the items in the questionnaire and their relation to the specific phases.

In terms of Table 9, P3.1 (Step 5 in the model the integration and alignment of executive management) has an aggregate mean which equates to $2.84(n=276)$. It is noteworthy that this particular aggregate mean is the highest of all the aggregate mean scores for all the phases and steps that formed part of the survey questionnaire. This implies that the participating institutions (NMMU and CPUT-DUT), as well as the functional categories (executive management, line management, HR practitioners and non-HR or non-line management), have individually and collectively considered the integration and alignment of executive management as the most important step in the eight-step integrated postmerged organisational culture creation model.

In the 'Institution' column, the means of NMMU $(2.83 ; n=136)$ and CPUT-DUT $(2.85 ; n=140)$ in total are relatively close to the aggregate mean score for this column, which suggests that respondents' perceptions at the two institutions in respect of the importance of aspects covered in this section of the questionnaire (Step 5 of the model), can be viewed as being very similar.
In the combined 'Functional category' column, the mean scores equate to 2.83 (EM-LM-HR; $n=99$ ) and 2.85 (other; $n=177$ ). These respective mean scores are relatively close to the aggregate mean of $2.84(n=276)$ for the combined 'Functional category' column, which suggests that the respondents' views of the importance of the aspects dealt with in this section of the questionnaire can be described as very similar, despite their different functional categories.

In the combined 'Institution: Functional category', the functional categories are separated and presented by institution. The 'EM-LM-HR' and 'other' categories at NMMU have mean scores equating to $2.85(n=46)$ and $2.83(n=90)$, respectively. These mean scores are relatively close to the aggregate mean score of $2.84(n=136)$ for this column, which suggests that the two functional categories at NMMU have expressed very similar perceptions in relation to importance of aspects dealt with in this section of the questionnaire. The 'EM-LM-HR' and 'other' categories at CPUT-DUT have mean scores equating to $2.85(n=53)$ and $2.84(n=87)$, respectively. Again, the mean scores for this column are relatively close to the aggregate mean score of $2.84(n=140)$ for this column, which suggests that the perceptions of the respondents are very similar in relation to the importance of aspects dealt with in this section of the questionnaire. The high mean score in relation to the integration and alignment of executive management is indicative of the high level of importance that respondents

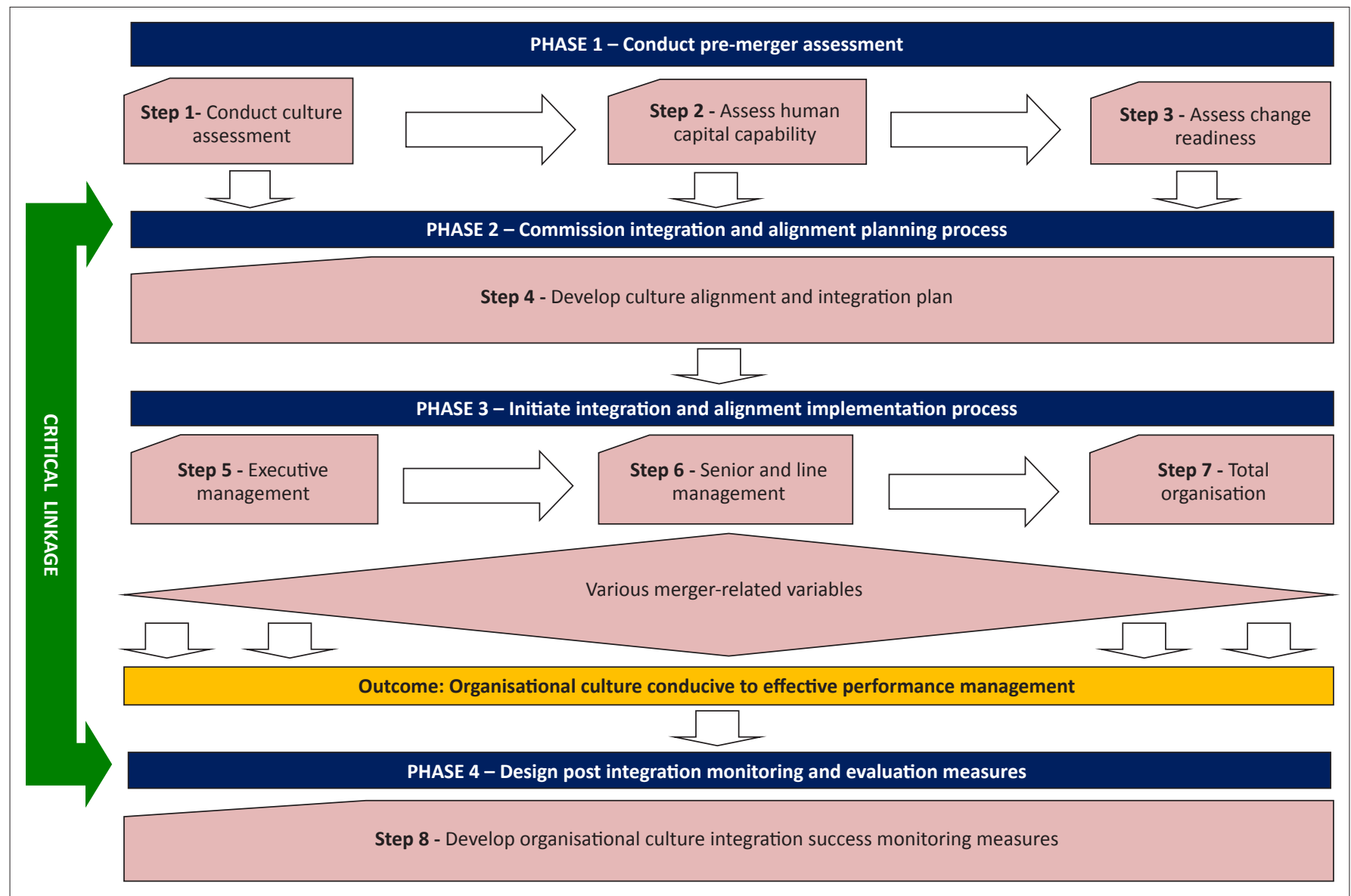

FIGURE 4: The eight-step integrated post-merged organisational culture creation model. 
Phase 1 - Conduct pre-merger assessments

Management of the organisations need to ensure that the aspects listed under the various steps are addressed (formally or informally) as part of the assessment process in Phase 1 of the model.

\section{Step 1 - Conduct a culture} assessment

Nature of institutional cultures

Compatibility of institutional cultures

Compatibility of information communication technology

Leadership orientations

Academic offering

\section{Step 2 - Assess the human} capital capability

Current and future human capital requirements

The prevailing performance management orientations

Nature and extent of reward and recognition systems

Nature and extent of key staff retention mechanisms

\section{Step 3 - Assess the level of} change readiness

Readiness to undergo intense change process

Reasons for resistance to change amongst employees

Nature of resistance amongst employees

Demands of change process on employees

Phase $\mathbf{2}$ - Commission integration and alignment planning process

Management of the organisations need to embark upon a planning process to integrate and align executive, senior and line management as well as the total organisation in a time-sensitive and legally compliant manner.

Step 4 - Develop culture alignment and integration plan

Identify all issues that are time-sensitive in nature such as legal, regulatory, competitive demand or broad system alignment Establish processes to support the integration and alignment of executive, senior as well as line management in the total organisation

Phase 3 - Initiate integration and alignment implementation process

The newly appointed executive management of the merged organisations need to ensure that the listed aspects are actualised to fast-track the integration and alignment process.

Step 5 - Align executive management

Executive management should take the lead in living the values of the merged organisation

Executive managers should provide leadership in developing, communicating and implementing the mission, vision and strategy of the merged institution

Executive managers should provide direction, motivation, guidance and clarity to employees in the merged organisation

Executive managers need to have meaningful conversations with all staff about the roadmap to creating a high performance merged institution

Executive and line managers should assist employees to adapt to the organisational culture of the merged institution

\section{Step 6 - Align senior and line} management

Managers should be expected to be the primary drivers of effective organisational behaviour in the merged institution

Managers should be expected to provide employees, through small-group sessions, with greater clarity about the direction and purpose of the merged organisation

Managers should be expected to gain employees' buy-in regarding behaviours and work practices that will strengthen the values of the merged institution

Managers should walk-the-talk through faultless behavioural modelling

\section{Step 7 - Align the total} organisation

Every employee should be given an opportunity to clearly understand the changes that are required to create a high performance post-merged institution

Every employee should be given an opportunity to clearly understand the mission, vision and values of the post-merged institution

Every employee in the merged institution should be given the opportunity to clearly understand the reasons for the merger

Every employee should be given an opportunity to clearly understand the direction of the merged institution

FIGURE 5: Details of the eight-step integrated post-merged organisation culture creation mode. 
Step 8 - Develop organisational culture integration success monitoring measures

Develop and communicate organisational culture integration success monitoring measures

Develop and communicate measures that will confirm an increase or decrease in profitability

Develop and communicate measures that will confirm an increase or decrease in financial viability

Develop and communicate measures that will confirm an increase or decrease in overall organisational performance

Develop and communicate measures that will confirm an increase or decrease in staff satisfaction

Develop and communicate measures that will confirm an increase or decrease in employee engagement

Develop and communicate measures that will confirm an increase or decrease in the retention of key staff

Establish focus groups to enable staff to express their views about the organisatioal culture integration

Develop and implement measures to track employees' adherence to the merged institution's values and behaviours

FIGURE 5 (Continues ...): Details of the eight-step integrated post-merged organisation culture creation mode.

attached to the role of executive management in a postmerged environment. This finding is consistent with the views expressed by Able (2007), Booz Allen Hamilton (2001), Macfarlane and Butterill (1999), Scanlan (2005) and Stahl (2004), in relation to the criticality of effective executive leadership during a merger. This study therefore not only corroborates the findings of previous studies regarding the role of executive leadership in a post-merged environment, but it also highlights the need for merged higher education institutions to continue building postmerged leadership capacity in order to support the creation of an organisational culture which is conducive to effective performance management in order to avoid merger failure.

The refined eight-step integrated post-merged organisational culture creation model thus emerges from the review of the quantitative results and is depicted in Figure 4. The integrated nature of the model is graphically illustrated by the vertical and horizontal arrows that connect the various process steps within and across the various phases. This suggests that the model might not achieve its intended outcome if only certain phases or process steps of the model are implemented in isolation. This contention has, in fact, been confirmed by testing the statistical significance of the correlations between the various process steps of the model (refer to Table 5). All the significant correlations are highlighted in bold. A more detailed discussion related to Table 5 was provided in the section entitled 'Results'. The outcome of the model (refer to the rectangular shape in Figure 4, situated between Phases 3 and 4) is described as an 'organisational culture conducive to effective performance management'. The model further illustrates that this outcome will be influenced by various merger-related variables, such as employees' age, clarity of the merger rationale, employee buy-in and stakeholder expectations.

Figure 5 provides details of the eight-step integrated postmerged organisational culture creation model. The details are arranged according to each phase and its associated process steps, as depicted in Figure 4. Phase 1 in Figure 5 deals with the conducting of pre-merge assessments, which include a culture assessment, human capital capability assessment and a change readiness assessment. The resulting data are to be utilised in Phase 2 (and Step 4), which deals with the commissioning of the integration and alignment planning process as well as the actual development of the culture alignment and integration plan. Phase 3 deals with the implementation of the culture integration and alignment process which entails the alignment of executive management (Step 5), alignment of senior and line management (Step 6) and alignment of the total organisation (Step 7).

\section{Practical implications and implementation opportunities of the research findings}

The findings flowing from this study have revealed several implications and implementation opportunities for organisations embarking upon a merger process. These implications and opportunities include the need for:

- Post-merged organisational culture integration and alignment to be executed in a structured and integrated manner, such as the approach outlined in the model illustrated in Figure 4.

- Pre-merger assessments, in respect of culture compatibility, human capital capability and change readiness, to be treated as important and be conducted either formally or informally.

- Executive management to be visibly leading the organisational culture integration and alignment process.

- A structured employee engagement programme to form an integral part of the organisational integration and alignment of the total organisation (refer to Step 7 in Figure 4).

Additionally, Figure 6 confirms the strong correlation between employee engagement and an organisation's financial prosperity in the form of return of assets, profitability and shareholder value (Macey, Schneider, Barbera \& Young, 2009). A specific intervention that could be considered in 


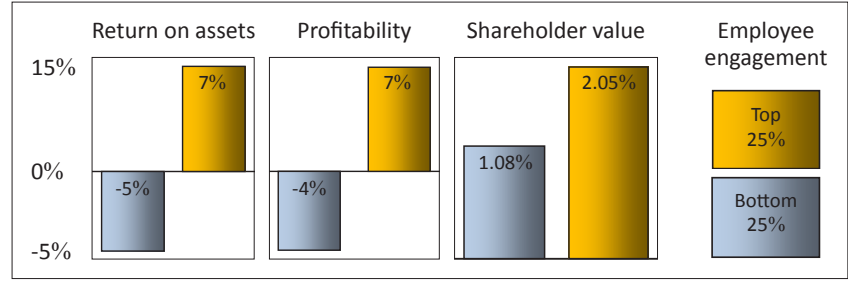

FIGURE 6: Employee engagement and financial performance comparisons.

supporting the employee engagement programme is known as positive organisational scholarship (POS), which focuses on the generative dynamics such as life-building, capability enhancing and capacity-creating in an organisation. These organisational dynamics could enhance human strengths and virtues, resilience and healing, vitality and thriving, as well as the cultivation extraordinary states in individuals, groups and organisations during times of organisational change such as mergers. The University of Michigan, which has implemented POS, reported a 'great deal of intellectual energy' from scholars across a spectrum of disciplines such as the Schools of Business, Education, Medicine, Public Health, Music, Literature, Science and Arts. Through various associations and interactions, which includes conferences, research initiatives and classroom teaching materials, collaborative research and shared ideas for application in their various disciplines have been fostered (Dutton, Glynn \& Spreitzer, 2006).

\section{Possible limitations of the study and directions for future research}

A possible limitation of the study is that it did not draw a distinction between the responses of academics and those of professional, administrative and support staff, regarding which aspects were included in the various sections of the questionnaire. This distinction could have provided useful insights into academics' perceptions regarding the merger, given their centrality to the core business of higher education institutions. This limitation could be addressed by specifically focusing on the integration and alignment of the academic cohort within post-merged higher education institutions, on the basis that academics are responsible for delivering on the core mandate of these institutions.

\section{Conclusion}

The insights gleaned from the findings of the empirical study show a strong congruence with the views in relation to the importance of effective executive leadership in the post-merged organisation to ensure the creation of an organisational culture which is conducive to effective performance management. The findings of the study further highlighted the need to attend to the particular aspects that are listed in Table 5, as part of executive management's role to ensure their own integration and alignment as part of the organisational culture creation process as advocated on the basis of the application of the eight-step integrated post-merged organisational culture creation model. The findings of this study corroborate other studies relating to the importance of an effective post-merged culture integration to support optimal performance management. It furthermore places particular emphasis on the importance of the role of executive leadership with regard to the various critical key pre-merger and post-merger related activities to support the creation of an organisational culture conducive to effective performance management.

\section{Acknowledgements}

The three institutions that participated in this study, namely the Nelson Mandela Metropolitan University, the Cape Peninsula University of Technology and the Durban University of Technology, are acknowledged for providing ethical clearance to conduct the empirical study amongst their employees.

\section{Competing interests}

The authors declare that they have no financial or personal relationship(s) which may have inappropriately influenced them in writing this paper.

\section{Authors' contributions}

G.W.P. (Nelson Mandela Metropolitan University) conducted the empirical research, literature review, statistical interpretation and reporting of results in various formats as well as various content contributions. D.M.B. (Nelson Mandela Metropolitan University) provided conceptual and content contributions as well as his generous support and encouragement.

\section{References}

Able, R.M. (2007). The importance of leadership and culture to merger and acquisition success. The human capital institute. Retrieved September 24, 2011, from http:// www.imaa-institute.org/docs/m\&a/towersperrin_09_the\%20importance $\% 20$ of\%20leadership\%20and\%20culture\%20to\%20M\&A\%20 success.pdf

Booz Allen Hamilton (2001). Merger integration: Delivering on the promise. A series of viewpoints on mergers, acquisitions and integration. Retrieved September 25, 2011, from http://www.boozallen.com/media/file/76776.pdf

Bresler, N. (2007). The challenge to reposition three divergent higher education institutions as a new comprehensive institution. South African Journal of Economic and Management Sciences, 10(2), 195-206

Brynard, P.A., \& Hanekom, S.X. (2006). Introduction to research in managementrelated fields. (2nd edn.). Pretoria: Van Schaik Publishers.

BuaNews (2003). Higher education mergers named. Retrieved January 24, 2012, from http://www.buanews.gov.za/news/12/12040412351001

Carleton, J.R., \& Lineberry, C.S. (2004). Achieving post-merger success: A stakeholder's guide to due diligence, assessment, and integration. San Francisco: Pfeiffer.

Council on Higher Education. (2000). Towards a new higher education landscape: Meeting the equity, quality and social development imperatives of South Africa in the $21^{\text {st }}$ century. Retrieved January 21, 2011, from http://www.che.ac.za/ documents/d000009/

Denison Consulting (2007). Reynolds American: A (rare) merger success story Retrieved May 17, 2010, from http://former.denisonconsulting.com/Libraries/ Resources/CS-2007-Reynolds-American.sflb.ashx

De Vos, A.S., Strydom, H., Fouche, C.B. \& Delport, C.S.L. (2005). Research at grass roots: For social sciences and human professions. (3rd edn.). Paarl: Paarl Print.

Dutton, J.E, Glynn, M.A., \& Spreitzer, G. (2006). Positive organisational scholarship. Retrieved March 11, 2011, from http://www.bus.umich.edu/Positive/PDF/ Dutton-POS-Encyc-of-Career-Devel.pdf

Floud, R., \& Corner, F. (2002). Managing a merger: Making it work for a university community. Retrieved September 24, 2011, from http://www.eua.be/eua/jsp/en/ upload/Case\%20LondonMet\%20Managing\%20a\%20Merger.1076688728905.pdf

Froneman, L. (2003). Managing change in higher educational institutions in South Africa: Some challenges. Retrieved January 02, 2010, from http://search.sabinet. co.za/WebZ/Authorize?sessionid=0\&bad=ejour/ejour_badsearch.html\&portal=ej ournal\&next=images/ejour/acom/acom_v3_a5.pdf

Goodboy, D. (2010). Pre-merger preparation. Retrieved September 23, 2011, from http://www.equity-buyout.com/?p=84

Hall, M., Symes, A., \& Luescher, T. (2004). The governance of merger in South African higher education. Retrieved June 11, 2011, from http://www.che.ac.za/ documents/d000072/Governance_of_Merger_HE_Aug2004.pdf 
Jansen, J. (2003). Mergers in South African higher education: Theorising change in transitional contexts. Retrieved January 12, 2011, from http://repository.up.ac. $\mathrm{za} / \mathrm{xmlui} / \mathrm{bitstream} /$ handle/2263/118/Jansen\%20(2003)a.pdf?sequence=3

Locke, W. (2007). Higher education mergers: Integrating organisational cultures and developing appropriate management styles. Higher Education Quarterly, 61(1) 83-102.

Macey, W.H., Schneider, B., Barbera, K.M., \& Young, S. (2009). Employee engagement: Tools for analysis, practice and competitive advantage. New York: Blackwell Press.

Macfarlane, D., \& Butterill, D. (1999). From principles to practice: The management of post-merger integration. Retrieved November 18, 2009, from http://www. longwoods.com/content/16959

Martin, A., \& Roodt, G. (2008). Perceptions of organisational commitment, job satisfaction and turnover intentions in a post-merger South African tertiary institution. SA Journal of Industrial Psychology/SA Tydskrif vir Bedryfsielkunde, 34(1), 23-31.

Meyers, M.D. (2009). Qualitative research in business management. Thousand Oaks: Sage Publications.

Muller, N.J. (2006). Merger and managers: What's needed for both to work? Reflections on a merger of two higher education libraries in KwaZulu-Natal. $S A$ Journal of Library and Information Science, 72(3), 198-207.

Ramphele, M. (2009). Laying ghosts to rest-Dilemmas of the transformation in South Africa. Cape Town: NB Publishers.
Roland Berger Strategy Consultants (2010). Pre-merger preparation and post-merger integration. Retrieved September 23, 2011, from http://www.rolandberger.com/ integration. Retrieved Septembertisunctional_issues/strategy_and_corporate_excelence/integration/

Saunders, M., Lewis, P., \& Thornhill, A. (2000). Research methods for business students. (2nd edn.). Harlow: Prentice-Hall.

Scanlan, L. (2005). Mergers: A critical test of leadership: Challenge yourself to excel at leadership during uncertain times. Retrieved January 14, 2011, from http://www. highbeam.com/doc/1G1-132536403.htm

Schultz, C.M. (2009). Building a human resource strategy for a merging higher education institution in South Africa. South African Journal of Labour Relations, 33(2), 11-18.

Simon, S. (2008). Measuring agreement. Retrieved January 11, 2011, from http:// www.childrensmercy.org/stats/weblog2004/CronbachAlpha

Stahl, G.K. (2004). Getting it together: The leadership challenge of mergers and acquisitions. Retrieved March 14, 2011, from http://onlinelibrary.wiley.com/ doi/10.1002/lia.1083/abstract

Struwig, F.W., \& Stead, G.B. (2001). Planning, designing and reporting research. Cape Town: Pearson Education.

Tobak, S. (2007). Why mergers fail. Retrieved September 24, 2011, from http://news. cnet.com/8301-13555_3-9796296-34.html

Welman, J.C., Kruger, S.J., \& Mitchell, B. (2005). Research methodology. (3rd edn.). Cape Town: Oxford Press. 